\title{
Sandman: Obertura
}

\section{Neil Gaiman, J.H. Williams iiI \\ y Cameron Stewart}

ECC, 2014-2016

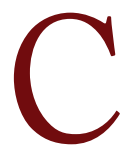

uando Neil Gaiman llegó en 1987 a DC Comics de la mano de Alan Moore, lo hizo continuando la senda abierta por el autor de $M i-$ racleman, a quien de hecho había sucedido al frente de aquella cabecera: la reinterpretación de los géneros clásicos a través de una sensibilidad más oscura, más cínica y más británica en el tratamiento de los temas. Muy pronto, en 1988, Gaiman aceptaría la propuesta de la editora Karen Berger y uniría fuerzas con Sam Kieth para alumbrar su creación más exitosa: The Sandman. Surgía bajo la apariencia de una puesta al día de ciertos personajes y conceptos de las viejas series de relatos de terror de DC Comics, pero enseguida quedó claro que The Sandman era el juguete de Gaiman, donde iba a volcar todas sus obsesiones e intereses. Se trata de una serie que - en este caso creo que podemos usar el tópico- marcó una época. Terror gótico, personajes con una actitud contemporánea, referencias a la cultu-

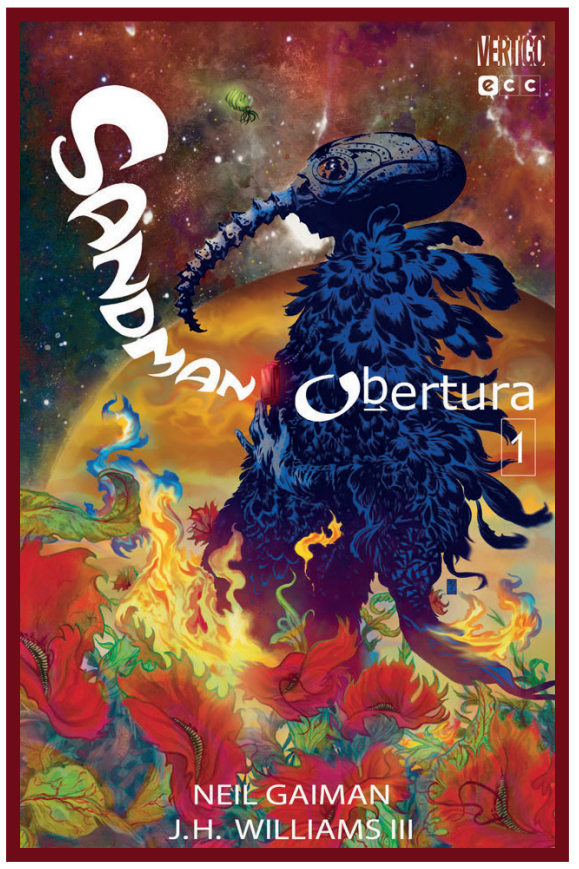
ra viva de su momento y a la tradición por igual... Pocas series como esta supieron entender el cambio de década y los intereses de una nueva adolescencia más descreída, a la que la rabia punk ya decía menos que los temas de Depeche Mode o The Cure, y que muy pronto empezaría a jugar a Vampiro: La Mascarada. Góticos y siniestros se acercaban así a una serie de una editorial de la que, seguramente, nunca habrían comprado un tebeo. Gaiman, de poderosa influencia literaria, con una habilidad incuestionable para escribir frases epatantes, sentencias que escribir en tu carpeta de clase - y no lo digo como crítica negativa- convirtió The Sandman en una serie perfecta para leer en esa época de la vida en la que piensas que eres diferente a todos los demás y nadie te comprende.

Por supuesto, sería injusto limitar el juicio sobre el trabajo de Gaiman a subrayar su ojo comercial. De hecho, cuando The Sandman comenzó, nadie podía imaginarse su éxito; tampoco el propio Gaiman. Además, su estética contemporánea estaba sustentada en sólidos cimientos culturales. Lo interesante de la serie siempre fue el contraste entre lo rabiosamente nuevo y lo atávico. Entre las ficciones posmodernas y las narraciones clásicas, las que nos hemos contado siempre. Gaiman, de amplia biblioteca, conoce en profundidad las 
estructuras narrativas, los motivos recurrentes y los símbolos que siempre van a conectar con la humanidad. Sabe hablar al subconsciente al tiempo que hace guiños a lo más efímero y transitorio. The Sandman trata de muchas cosas, pero una de sus claves es precisamente la creación de historias. No es la única, por supuesto. Por ejemplo, fue probablemente la primera ocasión en la que se naturalizaba la presencia de personajes homosexuales sin estereotipos ni tópicos negativos en el cómic mainstream, y sus personajes femeninos siempre fueron interesantes.

La saga de The Sandman, narrada con la colaboración de una atractiva plantilla de dibujantes - algunos de los más denostados por el fandom eran mucho mejores de lo que este pensaba-, quedó como un cómic clave de los años noventa, y sus contadas revisitaciones por parte de Gaiman — que se aseguró de que las explotaciones de su universo no tocaran a los personajes principales - no aportaron nada sustancial. Así que cabe preguntarse, casi veinte años después del final: ¿tiene sentido esta serie limitada que se propone como precuela de la serie original? Comercialmente, parece que sí: la miniserie, dentro de los estándares actuales, no ha vendido mal. ${ }^{1}$ Para Gaiman, cuyas incursiones en el cómic tras The Sandman han ido de lo intrascendente a lo mediocre, ha sido, aparentemente, un intento de volver a ser relevante en el medio en el que empezó a gestarse su fama. ¿Lo ha conseguido?

Veamos. Pese al relativo éxito comercial, la serie ha sido recibida con cierta apatía y desinterés por parte de la crítica. A buen seguro, la disparatada periodicidad ha contribuido a ello. Lo cual evidencia hasta qué punto carece de sentido publicar esta historia como una serie de seis números, más allá de las razones nostálgicas. Un libro con la historia completa habría tenido más sentido en el mercado actual, sin duda alguna, pero si se trataba de replicar la sensación que producía esperar mes tras mes para leer el The Sandman original, lo mínimo era, al menos, mantener un ritmo mensual. Nada impedía esperar a que los autores hubieran concluido la realización del último número para comenzar la publicación de la miniserie con esa cadencia.

Otra cuestión obviamente esencial es la elección del dibujante. A priori, yo defendí la participación de J. H. Williams III, dibujante de la interesante Promethea de Alan Moore, y por tanto alguien acostumbrado a trabajar con guiones complicados y prolijos y a mezclar ambientes urbanos con elementos mágicos y mitológicos. Sin embargo, el resultado es decepcionante. Más concretamente: abruma. Williams, que acomete la tarea con evidente entusiasmo y deseo de impactar, trabaja en composiciones de página barrocas y elaboradísimas, pero casi nunca con utilidad narrativa, y con un sentido estético discutible. Cuando casi cada página es un artefacto que busca la sorpresa del lector, al final, por supuesto, nada sorprende. Más bien aburre la sucesión de composiciones farragosas, y se agradecen las pocas páginas en las que la plantilla de viñetas es funcional y permite un respiro. Sí hay que reconocerle una habilidad especial para variar de estilo e imitar el de otros. El coloreado in-

${ }^{1}$ El primer número alcanzó el top 7 en el listado de Diamond, con algo más de 93000 ejemplares vendidos, tras lo cual la miniserie fue perdiendo compradores, hasta que el sexto y último número solo alcanzó el top 18, con unos 48000 ejemplares vendidos. Fuente: http://www.comichron.com/monthlycomicssales.html 




formático de Dave Stewart responde a los gustos actuales, y en ese sentido no es peor que el de un cómic de superhéroes medio, pero basta con extender sobre una mesa las seis portadas para verse inundado de una miríada de colores chillones con brillos y degradados aplicados sin control. Solo en algunos casos, por ejemplo en las secuencias en las que aparece el padre de Sueño en el número 4, su trabajo funciona muy bien, por apartarse de los colores realistas y abrazar las tonalidades planas del pop art.

Es interesante reflexionar sobre los motivos para que en esta precuela, que pretende recuperar el espíritu original, se opte por un dibujo detalladísimo y sofisticado, lleno de artificios y efectos. Porque, en realidad, la serie original era bastante sobria y contenida. Y me parece que esto se debe a que se está intentando responder más bien al concepto de la serie que tenemos en nuestro recuerdo, al halo de exquisitez que los años transcurridos han generado a su alrededor.

En las cuestiones argumentales hay una evidente intención de tocar la misma canción. Y utilizo este símil sobre todo porque, cuando leí el primer número, la sensación que tuve fue la de estar ante un viejo rockero que, años después de disolver su banda, vuelve a salir de gira con una nueva formación más joven, pero para tocar los mismos temas de siempre. Que es, en el fondo, lo que quieren sus fans: reverdecer laureles, recuperar sensaciones, alimentar la 
nostalgia. Gaiman sabe lo que tiene que tocar para hacernos cosquillas en los estómagos: en la primera página ya aparece una construcción sintáctica, "Quorian soñaba», que dispara mecanismos en nuestras memorias, como los acordes de un riff mítico. El Corintio es aterrador, Marvin es el entrañable golferas descarado, Lucien es el sirviente fiel. Por supuesto, ya en este primer número aparecen Destino y Muerte. Las páginas desplegables del final del episodio abundan en la aparatosidad del artefacto, y nos permiten vislumbrar diferentes versiones de Morpheus, que supone la única novedad en un cuadernillo que sabe a ya leído desde el principio.

A partir de ese primer número, que deja claro que no van a caber las sorpresas y que Gaiman no ha vuelto a su criatura para deconstruirla, ni mucho menos, el guionista británico embarca a Sueño en un viaje a través del universo, donde visita toda clase de mundos, y se asocia con nuevos compañeros de viaje. De inmediato nos damos cuenta de que si Gaiman vuelve a su personaje fetiche es para contar cuestiones relevantes sobre él. Dicho de otro modo: Sandman: Obertura tiene por objetivo principal responder a algunas de las incógnitas que la serie original dejó sin resolver. Responde así de un modo dócil, complaciente, al ansia fan por rellenar huecos, por no quedarse sin saber absolutamente nada de las ficciones a las que se dedica toda la atención. Pienso que es un error. Y me sorprende, porque de Gaiman esperaba que fuera consciente de que el poder de lo no narrado es inmenso, y nada que él pueda decirnos sobre determinadas cuestiones que quedaron en la sombra podrá superar lo que nuestra imaginación ha elaborado con el paso de los años. Esta obsesión explicativa, paradigmática de la ficción revisionista dirigida a antiguos fans de entre treinta y cuarenta años, que ha afectado tanto a Star Wars como a Watchmen, dirige esta precuela que, al menos, ha sido ideada por el creador original. De modo que podemos estar seguros de que lo que les sucede a los personajes es lo que Gaiman quiere que suceda. No es consuelo, claro; ninguno de los enigmas revelados tiene la suficiente fuerza como para justificar el misterio que los ha envuelto todo este tiempo, y que más allá de eso tenían un sentido narrativo claro en la serie original. Lo cierto es que ni la historia del primer Corintio, ni de Alianora —el viejo amor de Morpheus que aparecía fugazmente en $U n$ juego de $t i-^{2}$ ni las explicaciones que se dan a propósito de la ancestral enemistad entre Sueño y Deseo — que, a la postre, era la clave de la serie original - aportan nada significativo más allá de la satisfacción de la curiosidad del fan. Al contrario: la resolución resta poder evocador.

Estas historias están imbricadas en una única trama lineal y demasiado simple, en la que todo avanza mediante un desfile de personajes que a través de exposiciones y parlamentos —nunca de la acción — van ofreciendo a Morpheus la información que necesita para resolver el problema que enfrenta, justo antes de ser encerrado, tal y como aparece en el primer número de The Sandman fechado en enero de 1989.

Como decía, pienso que la irrelevancia de Sandman: Obertura tiene que ver con su anacronismo: no solo por el formato de comic book, sino también y sobre todo porque el mercado y el público han cambiado muchísimo, y esta serie permanece anclada en los primeros no-

${ }^{2}$ Gaiman, N. et alii. Un juego de ti. Barcelona, Norma Editorial, 2004. 
venta, más allá del lavado de cara estético. En aquella época, el lector de cómic mainstream no tenía muchas más series a las que acudir si quería leer historias con ciertas referencias culturales, personajes reales y temas profundos. Apareció en el momento justo y no es exagerado decir que la industria necesitaba The Sandman para abrir esa vía, que había anticipado el trabajo de Moore o de Grant Morrison, pero que Gaiman supo ampliar. Cumplió una función esencial. Pero hoy la publicación de esta serie llega a un panorama en el que hay mucho donde escoger, y donde sus hijos, confesos o no, campan a sus anchas. El lector de 2013 no necesitaba una serie que solo puede entenderse como celebración y ofrenda complaciente a los fans.

Con esto quiero decir también que debemos ser justos: incluso aunque Gaiman, Williams y Stewart hubieran firmado una de las mejores historias de The Sandman, el contexto actual habría minimizado su impacto. Lo que a los dieciocho años y en los años noventa parecía sofisticado, complejo y adulto, ahora expone sus costuras y parece pedante o artificioso. Y, sin embargo, aun así, si vuelvo a la serie original todavía veo una chispa, un ingenio en los diálogos, unas gotas de realismo sucio contrastando con el mito y un sentido del humor que aquí se han perdido, a favor de una supuesta majestuosidad que nunca he podido creerme lo más mínimo. Sandman: Obertura no quiere hablar a los adultos que somos hoy, pero tampoco consigue llegar a los adolescentes que fuimos. Da la sensación de que Gaiman nunca llega a ser capaz del todo de volver al mundo que creó, quizá porque también él ha cambiado. Y, al final, en esa indefinición está su gran fracaso.

Gerardo Vilches

Gerardo Vilches (Madrid, 1980) es licenciado en Historia, profesor y critico de cómics. Es uno de los responsables de Entrecomics y mantiene su blog personal, The Watcher and the Tower, desde 2007. Colabora en la revista Rockdelux. Participa en la organización de GRAF y coordina diversas actividades relacionadas con el cómic. Ha contribuido con sus textos en Panorama. La novela gráfica española hoy (Astiberri, 2013), Radiografía de una explosión. Doce aproximaciones concéntricas a Watchmen (Modernito Books, 2013) e Hijos del átomo (Alpha Decay, 2015). Es autor de Breve historia del cómic (Nowtilus, 2014) y El guión de cómic (Diminuta Editorial, 2016). Codirige $\mathrm{CuCo}$, Cuadernos de cómic junto a Octavio Beares. 